\title{
ELECTRICAL LOAD RELIABILITY ASSESSMENT USING ANALYTICAL METHOD, CASE STUDY: FUPRE 1 X 2.5MVA INJECTION SUBSTATION
}

\author{
AMAKIRI OKILO FRIDAY ${ }^{1}$, OSHEVIRE PATRICK*1 \\ ${ }^{1}$ Department of Electrical and Electronic Engineering, College of Technology, Federal \\ University of Petroleum Resources, Effurun, Warri, Delta State, Nigeria.
}

\begin{abstract}
This research work presents the reliability assessment of electrical load distribution system in Federal University of Petroleum Resources, Effurun (FUPRE), Warri using the Analytical method and ETAP software as the simulation tool to run the reliability assessment of the System. The analytical analysis was conceded out by using August 2018 - August 2019 historical data of Tetfund Classrooms Blocks, Hostels, College of Technology, Administration Block, Health Center, and College of Science Feeder obtained from the Benin Electricity Distribution Company [BEDC]. The results conceded revealed that College of Technology Injection Substation is the most reliable in the distribution network when compared to the other five substations around the institution premises as it recorded system indices of ASAI: 99.30, SAIFI: 1.10, SAIDI: 55.35, CAIDI: 123.04 in August 2018 to August 2019. Nevertheless, the total reliability indices of the six substations under investigation as obtained from the analysis, and it shows that availability of power to FUPRE distribution is very poor as compared with the benchmark of IEEE ASAI of 99.99 for distribution substation availability.
\end{abstract}

Keywords: reliability assessment, availability of power, distribution system, reliability indices, load point indices, system indices and ETAP

\section{INTRODUCTION}

Reliable electric power supply is the bases for modern society. The fundamental capacity of a distribution system is to supply constant electricity to its customers at optimal operating costs with the affirmation of a reasonable quality and congruity consistently at all times. Power system reliability depicts the general capacity of the distribution system to execute its purpose sufficiently. Usually power distribution system reliability discussions are divided into two separate perspectives, security and sufficiency [1].

Power adequacy can be characterized as the presence of adequate facilities to fulfil the demand. Acceptability of a power distribution system is identified to static conditions, and is normally evaluated through power flow simulation studies. Security of power system reflects the capacity to respond to disturbances, henceforth, the safety of a power distribution system relates to the system vibrant response and can be through unique studies [2].

Electric power system is essentially set up to supply electric power with little or zero interruptions to its consumers. The number of interruptions that happen while the electric power distribution system executes its intended function is part of what determines the widespread reliability of the system. The different issues that determines its unwavering quality reliability is the quality of electrical power conveyed. Moreover, the ability of a power system

\footnotetext{
* Corresponding author, email: oshevire.patrick@ fupre.edu.ng

(c) 2020 Alma Mater Publishing House
} 
to persistently convey quality electricity implies that the consumers are fulfilled, and the power suppliers are having favorable incomes on their investment as they proceed their business of delivering electricity. As power utilization has become a significant factor that influences the drive desired for technology to grow and to motivate the improvement of modern society, it significant hence to pay attention to the difficulty of reliability of an electric power distribution system [3-5].

Electric Generation, transmission and distribution are the three subsystems of an electric power distribution network. Truth be told, a conventional electrical power system is centralized in terms of control and transmission of electrical power, the electrical energy produced by the generators in power plants flows over the grid from transmission and distribution system down to the consumers, as seen in Figure 1.

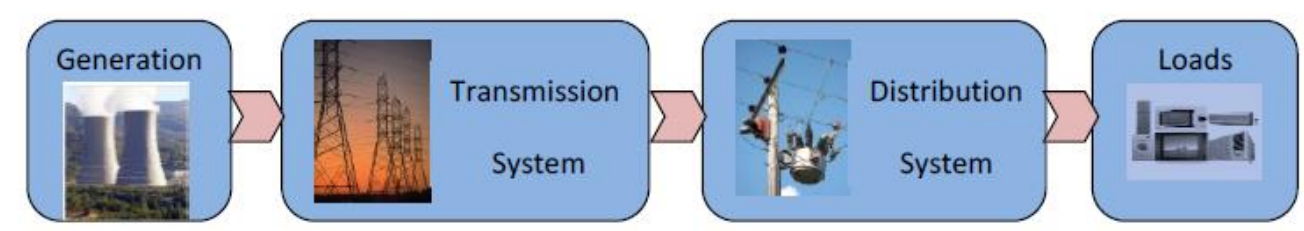

Fig. 1. Power flow of a conventional power system.

In reliability analysis, electrical power distribution systems are frequently divided into three components to characterize the limits of the reliability assessment. These components are alluded to as hierarchical levels and can be portrayed as appeared in Figure 2.

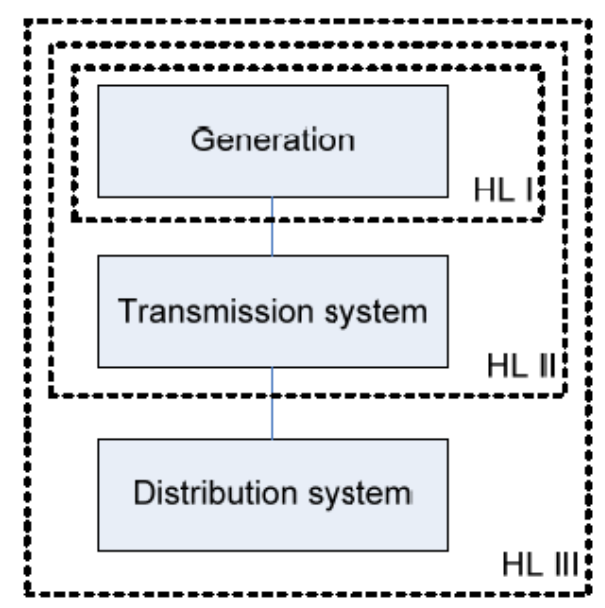

Fig. 2. Power System Hierarchical Levels [6].

Hierarchical level I (HL I) comprises solely generation and load of the distribution system. Resolute reliability study of HL I is an assessment of the overall system generating capacity essential so as to fulfil the normal system demand.

Hierarchical level II (HL II) is in the power system steadfast reliability field frequently, many instances referred to as the "bulk power system", including electrical generation and transmission. Henceforth, a steadfast reliability study of HL II assesses the generation and transmission ability to supply the power distribution system load (circulated in bulk load points). Hierarchical level III (HL III) includes the entire power distribution systems (generation, transmission and distribution). Because of the complexity and size of the power distribution system, an unwavering reliability study of HL III is ordinarily reasonable for little systems [5].

Sufficiency evaluation at HL1 is concerned about just the ampleness of generation to meet the system load requirements and the territory of activity is typically termed as generating capacity reliability assessment. Both generation and associated transmission equipment are considered at HLII adequacy evaluation is occasionally alluded to as composite system or bulk system adequacy assessment. HLIII adequacy evaluation includes the 
consideration of all three utilization areas in trying to assess customer load point sufficiency. In this manner, Assessment of HLIII is along these seen as overall power system adequacy evaluation [6].

The principle function of an electrical power system is to supply electric power to its customers at optimal operating costs with the affirmation of a good quality and continuity consistently [7]. Reliability is the likelihood that a power system will perform its capacities sufficiently with no disappointment within a stipulated period when subjected to normal working conditions [8]. The reliability study can be used to survey the performance of the power distribution system based on the accessibility of reasonable input information of component data and the setup of the system. The dependability evaluation can likewise be utilized to identify the malfunctioned components that need dire substitution in the distribution system as well as proposing the numbers of new components that ought to be incorporated in order as to improve the unwavering reliability of the networks [9].

The inspiration behind this paper is to set up an extensive outline of the field of the subject of analytical electric power system dependable evaluation of the FUPRE network, for maximum values of the fullerene yield (fullerene mass proportion in the soot) and of the productivity.

\section{MATERIALS AND METHODS}

\subsection{Materials}

The materials used in this paper are the recorded information of the six (6) distribution injection substations within the university network under review. These data covered the period of one year (August 2018 - August 2019), were gotten from the day to day operational report of the six (6) substations owned by Benin Electricity Distribution Company (BEDC).

\subsubsection{Network Description}

The network under review is the $2.5 \mathrm{MVA}, 33 / 11 \mathrm{kV}$ situated at an institution (FUPRE). The institution is situated in Effurun, Delta State, Nigeria. It get its supply from Effurun Transmission Substation $33 \mathrm{kV}$ feeder. The incoming goes into the 2.5 MVA transformer situated in the university premises. Figure 3 shows the 2.5 MVA substation and its accessories.

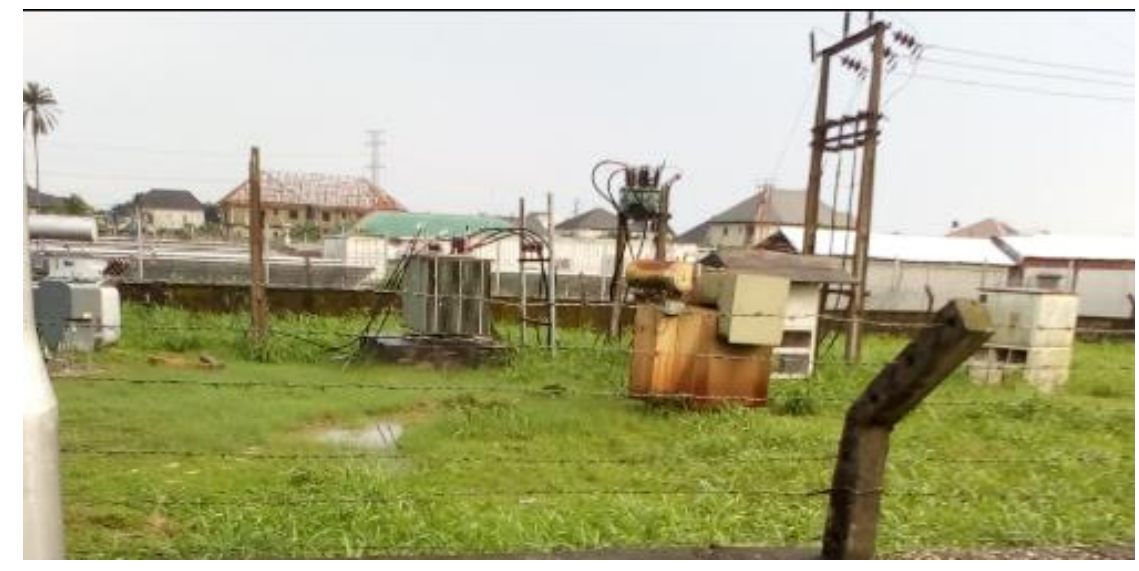

Fig. 3. MVA Transformer and its accessories.

The 2.5 MVA transformer feeds six (6) substations within the university premises. They are one (1) MVA transformer situated behind the administration block, five (5) numbers of $500 \mathrm{kVA}, 11 / 0.415 \mathrm{~V}$ transformers situated at, hostels, health center, Tetfund Classroom Buildings, college of Science and college of Technology buildings. Figure 4 shows a $500 \mathrm{kVA}, 11 / 415 \mathrm{~V}$ substation situated at the college of technology and Figure 5 shows the entire FUPRE network in ETAP software. 


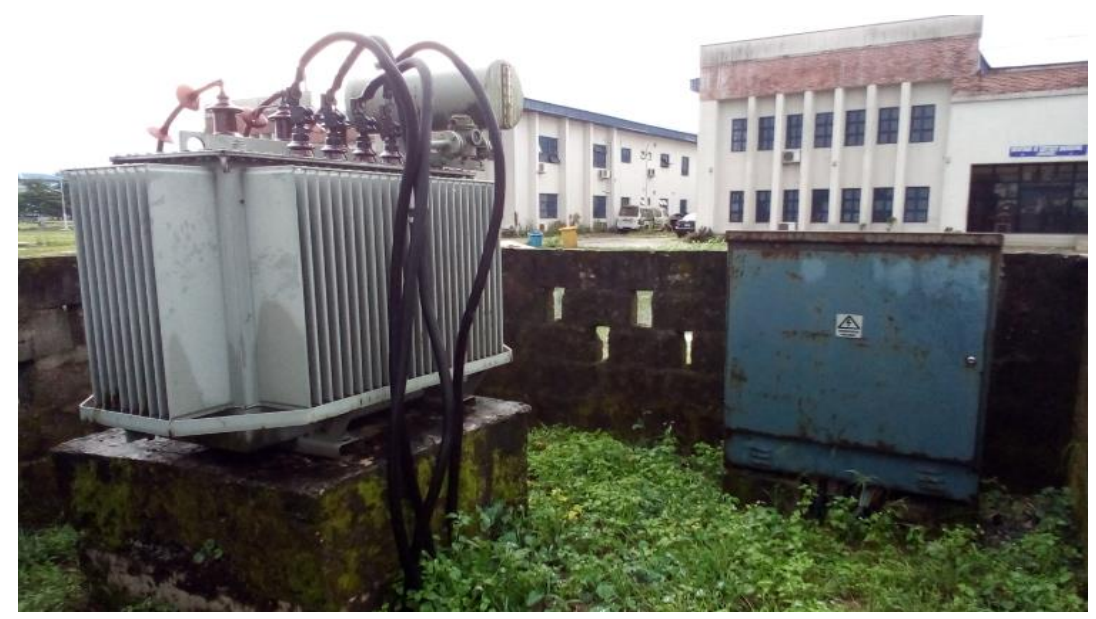

Fig. 4. 500kVA, 11/415V Transformer situated at College of Technology.

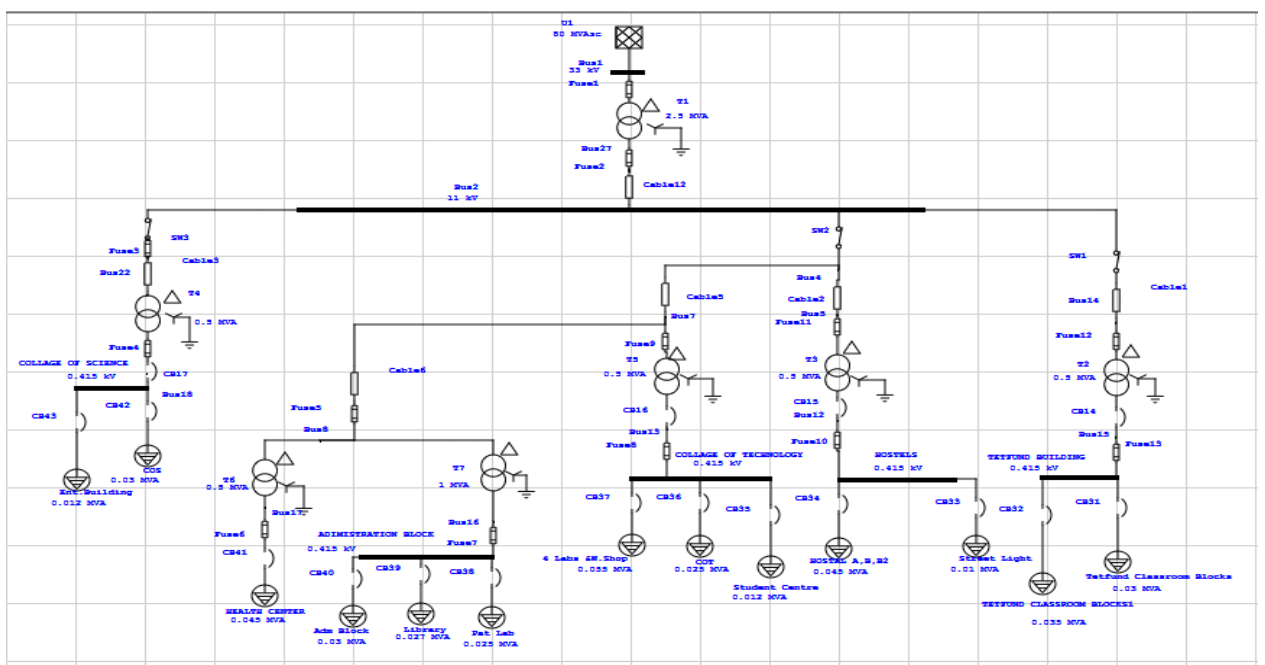

Fig. 5. Presents the single line diagram of the entire FUPRE Network in Electrical Transient Analyzer Programme (ETAP).

\subsection{Method}

In general, reliability assessment investigation can be accomplished either logically or arithmetically, although this paper just treats explanatory methods.

In investigative approaches, the system is characterized by mathematical prototypes, which are ordinarily built on Markov models. The expectancy values of reliability indices are determine by resolving an equation system.

The utmost numerical method is the Monte Carlo simulation technique. In this routine, the indiscriminate behavior of the structure is evaluated over model of somatic interactions. The result of a Monte Carlo simulation is the anticipation assessment possibility distributions of reliability indices, i.e. not only the regular values as in investigative procedures. The method presents the opportunity to apply more refined element prototypes, e.g. as well as properties of element aging. Nevertheless this hints to better computation time.

The Systematic Procedure signifies the system by a basic mathematical prototype and assesses the reliability indices from this model using direct mathematical elucidations. The systematic method is nevertheless used for this paper and the Electrical Transient Analyzer Program (ETAP) was employed for the system study.

\subsubsection{Reliability indices}

A Secondary distribution system is that aspect of the power system which links the bulk system to the individual consumers. The distribution system reliability indices analysis is normally concerned with adequate electric power supply at the consumer load point. 
The fundamental distribution system reliability indices are the three load point indices, Average Failure Rate, $(\lambda)$, the Average Outage Duration, (r) and the Annual Outage Duration, $(\mu)$.

\subsubsection{Load point indices}

The simple equations for computing the reliability indices at each load point, $\mathrm{P}$ are consequently:

Average Failure Rate at load point, p:

$$
\lambda_{P}=\frac{\Sigma \mathrm{F}}{T}(\mathrm{f} / \mathrm{yr} .)
$$

where $\mathrm{F}$ are load point failure frequency $\mathrm{T}$ are Operating Time (a calendar year. i.e., $365 \times 24 \mathrm{hrs}=8,760 \mathrm{hrs}$ ).

Annual Outage Duration at load point, p:

$$
\mu_{P}=\frac{\Sigma T d x}{T}(\mathrm{hr} / \mathrm{yr} .)
$$

where Tdx are Load point annual Down time (in hours), $\mathrm{T}$ are Operating Time.

Average Outage Duration at Load Point, p:

$$
r_{P}=\frac{\mu_{P}}{\lambda_{P}}(\mathrm{hr} .)
$$

Load Point Mean Time before Failure:

$$
M T B F=\sum \frac{T}{F}
$$

where $\mathrm{T}$ are Operating Time and $\mathrm{F}$ are failure frequency.

Mean Time to Repair:

$$
M T T R=\sum \frac{T d x}{F}
$$

where Tdx are Load point annual Down time (in hours), F are Load point failure frequency.

\subsubsection{System Indices}

The system indices normally used by utilities are SAIDI, SAIFI, ASAI and CAIDI. These indices can be considered using the simple load point indices. I.e., Annual Outage Duration, $(\mu)$, Average Failure Rate, $(\lambda)$, the Average Outage Duration, (r) and the Annual Outage Duration, $(\mu)$.

System Average Interruption Frequency Index:

$$
S A I F I=\frac{\Sigma \lambda_{T} \cdot N_{T}}{\Sigma N_{T}}\left(\frac{f}{\text { cust }}-y r\right)
$$

where $\lambda_{\mathrm{T}}$ are Failure rate, $\mathrm{N}_{\mathrm{T}}$ are No of consumers connected to load point, $\mathrm{p}$.

System Average Interruption Duration Index:

$$
S A I D I=\frac{\Sigma \mu_{T} \cdot N_{T}}{\Sigma N_{T}}\left(\frac{\mathrm{hr}}{\text { cust }}-y r\right)
$$

where $\mu_{T}$ are Annual Outage Duration at Load point, $\mathrm{p}, \mathrm{N}_{\mathrm{T}}$ are No of consumers connected to load point, $\mathrm{p}$.

Customer Average Interruption Index:

$$
C A I D I=\frac{\Sigma \mu_{T} \cdot N_{T}}{\Sigma \lambda \mathrm{T} \cdot N_{T}}(h r / \text { cust }- \text { int })
$$


Average Service Availability Index:

$$
A S A I=\frac{\Sigma N_{T} .8760-\Sigma \mu_{T} \cdot N_{T}}{\Sigma N_{T} .8760}(\%)
$$

where 8760 is the operational time, (i.e., the No of hours in a almanac year, 365 x 24 hrs.)

\subsection{Case Study}

The substation under review consist of one (1) Transformer which have capacity of 2.5 MVA and has six (6) distribution substation connected to it namely Collage of Science, Health Centre, Administration Block, College of Technology, Hostels and TETFUND Classroom Blocks.

The system is a $33 / 11 \mathrm{kV}$ power distribution substations which has a total number of 6,813 customers connected to $6 \times 11 / 0.415 \mathrm{~V}$ outgoing transformers or feeder, and it has been simulated by using the reliability assessment model of ETAP 16.00 software. The circuit was constructed using all required data and parameters as shown in the single line diagram in the Figure 6.

\subsubsection{Reliability Indices Calculation}

The reliability indices for the system is manually calculated to demonstrate how the dependable module of ETAP software calculate the indices. This could be achieved in using the historic data of the network system is shown in Table 1 by using reliability equation (1) to (9).

\subsubsection{Average failure rate at load point $T$ (Administration Block)}

Average failure rate at load point T (Administration Block):

$$
\lambda_{T}=\frac{\Sigma f}{T}=\frac{804}{8760}=0.1032 f / y r
$$

Annual outage duration:

$$
\mu_{T}=\frac{\Sigma T d x}{T}=\frac{6475}{8760}=0.7393 \mathrm{hrs} / \mathrm{yr}
$$

Average outage duration:

$$
\gamma_{T}=\frac{\mu_{T}}{\lambda_{T}}=\frac{0.7392}{0.1032}=7.162 \mathrm{hrs}
$$

Mean Time before Failure:

$$
M T B F=\frac{T}{\Sigma f}=\frac{8760}{904}=9.69 \mathrm{hrs}
$$

Mean Time to Repair:

$$
M T T R=\sum \frac{T d x}{F}=\frac{6475}{904}=7.163 \mathrm{hrs}
$$

2.3.3. Average failure rate at Load Point T (College of Science) Average failure rate at Load Point T (College of Science):

$$
\lambda_{T}=\frac{\Sigma f}{T}=\frac{882}{8760}=0.1007 \mathrm{f} / \mathrm{yr}
$$

Annual outage duration:

$$
\mu_{T}=\frac{\Sigma T d x}{T}=\frac{4414}{8760}=0.5039 \mathrm{hr} / \mathrm{yr}
$$

Average outage duration at load point:

$$
\gamma=\frac{\mu_{T}}{\lambda}(\mathrm{hr})=\frac{0.5039}{0.1007}=4.850 \mathrm{hr} / \mathrm{yr}
$$


Mean Time before Failure:

$$
M T B F=\frac{T}{\Sigma f}=\frac{8760}{882}=9.932 h r s
$$

Mean Time to Repair:

$$
M T T R=\sum \frac{T d x}{F}=\frac{4.414}{882}=5.005 \mathrm{hrS}
$$

2.3.4. Average Failure rate at load point T (College of Technology)

Average Failure rate at load point T (College of Technology):

$$
\lambda_{T}=\frac{\Sigma f}{T}=\frac{965}{8760}=0.1102 \mathrm{f} / \mathrm{yr}
$$

Annual outage duration:

$$
\mu_{T}=\frac{\Sigma T d x}{T}=\frac{5951}{8760}=0.6793 \mathrm{hrs} / \mathrm{yr}
$$

Average outage duration:

$$
\gamma=\frac{\mu_{T}}{\lambda_{T}}=\frac{0.6793}{0.1102}=6.1643 \mathrm{hrs}
$$

Mean Time before Failure:

$$
M T B F=\frac{T}{\Sigma f}=\frac{8760}{965}=9.078 h r s
$$

Mean Time to Repair:

$$
\operatorname{MTTR}=\Sigma \frac{T d x}{F}=\frac{5951}{965}=6.167 \mathrm{hrs}
$$

2.3.5. Average Failure rate at load point $T$ (Hostel)

Average Failure rate at load point $\mathrm{T}$ (Hostel):

$$
\lambda_{T}=\frac{\Sigma f}{T} \quad=\frac{588}{8760}=0.0671 \mathrm{f} / \mathrm{yr}
$$

Annual outage duration:

$$
\mu_{T}=\frac{\Sigma T d x}{T}=\frac{4819}{8760}=0.5501 \mathrm{hrs} / \mathrm{yr}
$$

Average outage duration:

$$
\Upsilon=\frac{\mu_{T}}{\lambda_{T}}=\frac{0.5501}{0.0671}=8.198 h r s
$$

Mean Time before Failure:

$$
M T B F=\frac{T}{\Sigma f}=\frac{8760}{588}=14.898 \mathrm{hrs}
$$

Mean Time to Repair:

$$
\operatorname{MTTR}=\sum \frac{T d x}{F}=\frac{4819}{588}=8.196 \mathrm{hrs}
$$

2.3.6. Average Failure rate at load point T (Tetfund Classroom Block I) Average Failure rate at load point T (Tetfund Classroom Block I): 


$$
\lambda_{T}=\frac{\Sigma f}{T}=\frac{589}{8760}=0.0672 \mathrm{f} / \mathrm{yrs}
$$

Annual outage duration:

$$
\mu_{T}=\frac{\Sigma T d x}{T}=\frac{1985}{8760}=0.2266 h t s / y r
$$

Average outage duration:

$$
\Upsilon=\frac{\mu_{T}}{\lambda_{T}}=\frac{0.2266}{0.0672}=3.372 \mathrm{hrs}
$$

Mean Time before Failure:

$$
M T B F=\frac{T}{\Sigma f}=\frac{8760}{589}=14.873 \mathrm{hrs}
$$

Mean Time to Repair:

$$
M T T R=\frac{T d x}{F}=\frac{1985}{589}=3.37 \mathrm{hrs}
$$

2.3.7. Average Failure rate at load point $T$ (Health Centre) Average Failure rate at load point $\mathrm{T}$ (Health Centre):

$$
\lambda_{T}=\frac{\Sigma f}{T}=\frac{620}{8760}=0.0708 \mathrm{f} / \mathrm{yr}
$$

Annual outage duration:

$$
\mu_{T}=\frac{\Sigma T d x}{T}=\frac{4892}{8760}=0.559 \mathrm{hr} / \mathrm{yr}
$$

Average outage duration:

$$
\Upsilon=\frac{\mu_{T}}{\lambda_{T}}=\frac{0.559}{0.0708}=7.896 \mathrm{hrs}
$$

Mean Time before Failure:

$$
M T B F=\frac{T}{\Sigma f}=\frac{8760}{620}=14.129 \mathrm{hrs}
$$

Mean Time to Repair:

$$
M T T R=\sum \frac{T d x}{F}=\frac{4892}{620}=7.89 h r s
$$

\subsection{System indices}

The reliability assessment indices of the Institution system are calculated using equations (6) to (9). Applying these equations yields.

2.4.1. System Average Interruption Frequency Index (SAIFI)

College of Science (COS):

$$
S A I F I=\frac{\Sigma \lambda_{T} \cdot \mathrm{N}_{T}}{\Sigma \mathrm{N}_{T}}=\frac{(1.1025 \times 2299)+(1.1105 \times 869)}{2299+869}=1.105 f / \text { Cust }-y r
$$

2.4.2. System Average Interruption Duration Index (SAIDI)

System Average Interruption Duration Index (SAIDI): 


$$
S A I D I=\frac{\Sigma \mu_{T} \cdot \mathrm{N}_{P}}{\Sigma \mathrm{N}_{T}}=\frac{(135,6851 \times 2299)+(136.5651 \times 869)}{2299+869}=135.93 \mathrm{hrs} / \mathrm{Cust}-y r
$$

\subsubsection{Customer Average Interruption Index (CAIDI)}

Customer Average Interruption Index (CAIDI):

$$
\text { CAIDI }=\frac{\Sigma \mu_{T} \cdot \mathrm{N}_{T}}{\Sigma \lambda_{T} \mathrm{~N}_{T}}=\frac{(135.6851 \times 229)+(136,5651 \times 869)}{(1.1025 \times 2299)+(1.1105 \times 869)}=\frac{123.04 \mathrm{hrs}}{\text { Cust }} . \text { Int }
$$

\subsubsection{Average Service Availability Index (ASAI)}

Average Service Availability Index (ASAI)

$$
A S A I=\frac{\Sigma \mathrm{N}_{T} .8760-\Sigma \mu_{T} \cdot \mathrm{N}_{T}}{\Sigma \mathrm{N}_{T} .8760}=\frac{(3,169 \times 8760)-(135.6851 \times 2299)+(136.5651 \times 869)}{3,169 \times 8760}=0.98449 \times 100=98.45 \%
$$

where 8760 is the operational time (i.e. the no of hours in a calendar year $365 \times 24 \mathrm{hrs}$ ).

\section{RESULTS}

The power distribution network under evaluation has modelled and simulated using Reliability Assessment model of ETAP as shown in Figure 6. The historical data used for modelling of this substation under review is shown in Table 1 which were used to run the simulator and different results were obtained are shown in table below. The Table 2 present the Load Point Indices of the Distribution Network.

Table 1. Historical Data of the Distribution System

\begin{tabular}{|l|c|c|c|c|c|}
\hline \multicolumn{1}{|c|}{ Load point } & $\begin{array}{c}\text { Failure } \\
\text { Frequency }\end{array}$ & $\begin{array}{c}\text { Annual Downtime } \\
\text { (hrs.) }\end{array}$ & $\begin{array}{c}\text { Annual Uptime } \\
\text { (hrs.) }\end{array}$ & No of Customers & Customer Type \\
\hline Collage of Science Building & 882 & 4414 & 3134 & 2299 & Offices/Labs \\
\hline Collage of Technology Building & 965 & 5951 & 6886 & 85 & Offices \\
\hline Health Centre & 620 & 4592 & 4206 & 57 & Commercial \\
\hline Hostels & 588 & 4819 & 5507 & 528 & Residential \\
\hline TETFUND Classroom Block 1 & 589 & 1985 & 2952 & 146 & Offices/Labs \\
\hline Administration Block & 904 & 6475 & 5180 & 92 & Offices \\
\hline Entrepreneurship Building & 492 & 2802 & 3521 & 869 & Offices/Labs \\
\hline Library & 648 & 5208 & 4801 & 180 & Offices \\
\hline Petroleum Lab & 538 & 3935 & 2890 & 828 & Offices/Labs \\
\hline 4 Labs \&Workshop & 9818 & 9670 & 7904 & 1380 & Offices/Labs \\
\hline Student Centre & 3956 & 4718 & 3902 & 47 & Offices \\
\hline Streetlight & 2,984 & 1869 & 2957 & 192 & Lights \\
\hline Tetfund Classroom Block 2 & 6792 & 4891 & 3619 & 110 & Offices \\
\hline
\end{tabular}

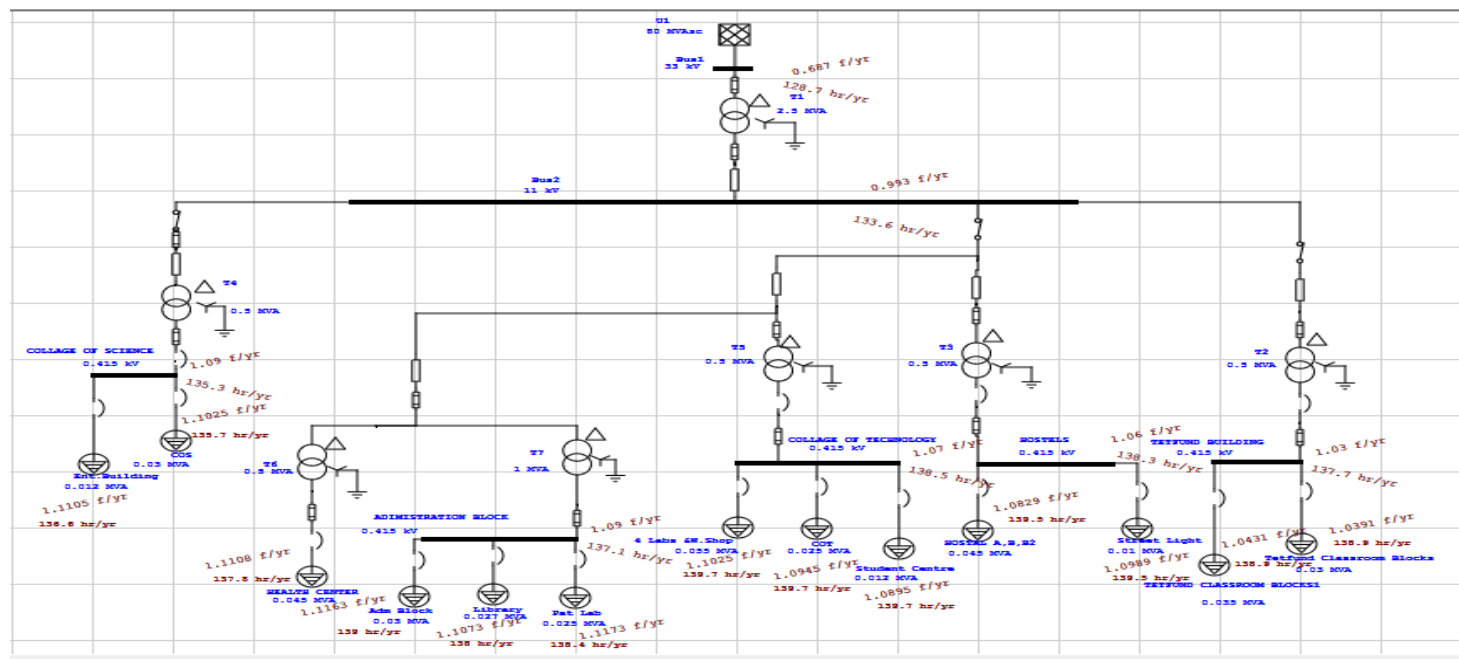

Fig. 6. Fupre Distribution Network in ETAP 16.00 Simulation Environment. 
Table 2. Load Point Indices of the Distribution Network

\begin{tabular}{|l|c|c|c|}
\hline Load Point & $\lambda_{T}(\mathbf{f} / \mathbf{y r})$ & $\gamma_{T}(\mathbf{H o u r s})$ & $\mu_{T}(\mathbf{f} / \mathbf{y r})$ \\
\hline Hostels & 1.0829 & 128.83 & 139.5043 \\
\hline Street Light & 1.0989 & 126.95 & 139.5046 \\
\hline Collage of Science Building & 1.1025 & 123.08 & 135.6851 \\
\hline Entrepreneurship Building & 1.105 & 122.98 & 136.5651 \\
\hline 4Labs \& W.Shop & 1.1025 & 126.71 & 139.6933 \\
\hline Collage of Technology & 1.0945 & 127.62 & 139.6789 \\
\hline Students Centre & 1.0895 & 128.22 & 139.6943 \\
\hline Administration Block & 1.1163 & 124.50 & 138.9746 \\
\hline Library & 1.1073 & 124.65 & 138.0197 \\
\hline Petroleum lab & 1.1173 & 123.84 & 138.3607 \\
\hline Health Centre & 1.1108 & 124.02 & 137.7600 \\
\hline Tetfund Classroom Block 1 & 1.0431 & 133.19 & 138.9302 \\
\hline Tetfund Classroom Block II & 1.0391 & 133.70 \\
\hline
\end{tabular}

Table 3 present the System Indices of the Substation under Review.

Table 3. System Indices of the Substation under Review

\begin{tabular}{|c|c|c|c|c|}
\hline Substation & SAIFI (Int/yr.) & SAIDI (Hrs. /yr.) & CAIDI (Hrs./Cust.Int) & ASAI (\%) \\
\hline College of Science & 1.11 & 135.93 & 123.04 & 98.45 \\
\hline College of Technology & 1.10 & 60.98 & 55.35 & 99.30 \\
\hline Hostels & 1.09 & 139.50 & 128.32 & 98.41 \\
\hline Tetfund Classroom Blocks & 1.04 & 138.93 & 133.41 & 98.41 \\
\hline Health Centre & 1.11 & 137.76 & 124.02 & 98.43 \\
\hline Administration Blocks & 1.12 & 138.54 & 124.19 & 98.42 \\
\hline
\end{tabular}

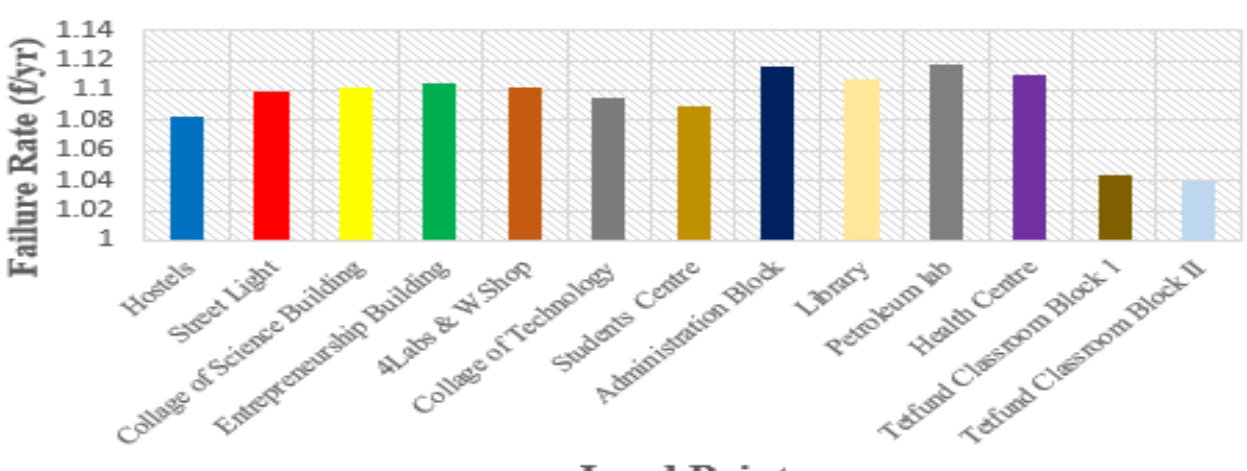

\section{Load Points}

Fig. 7. Failure Rate with Respect to Load Points.

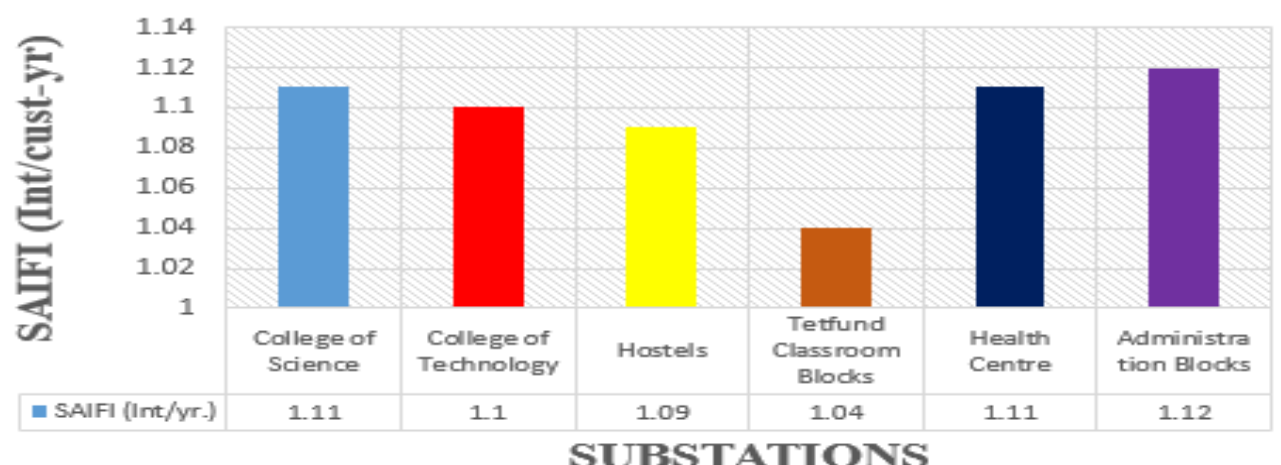

Fig. 8. SAIFI with Respect to Substation. 


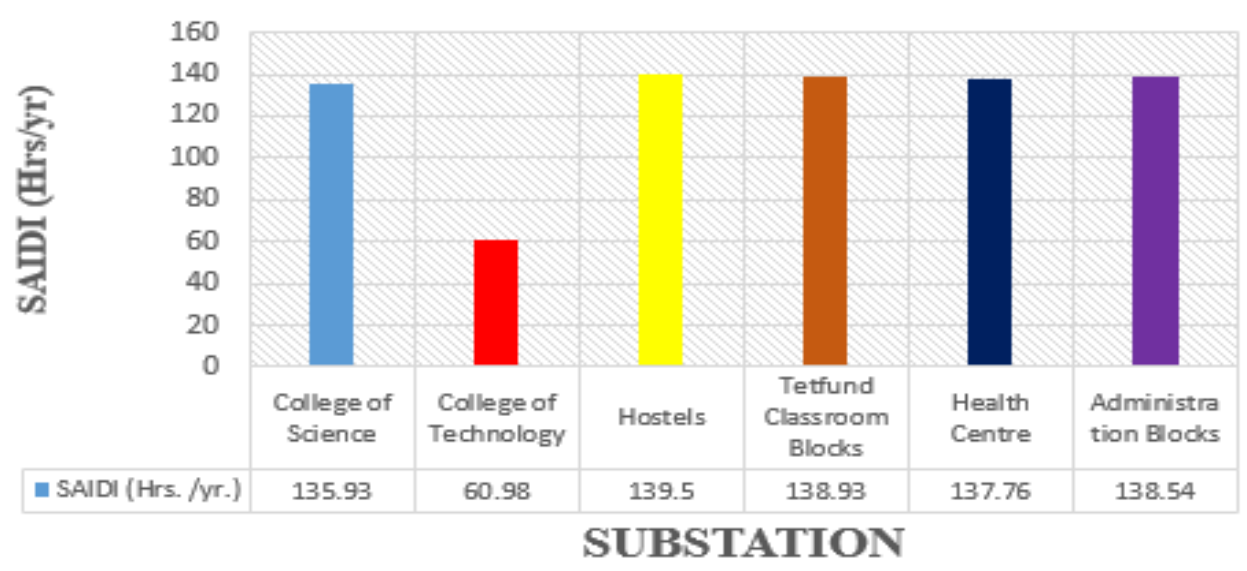

Fig. 9. SAIDI with Respect to Substation.

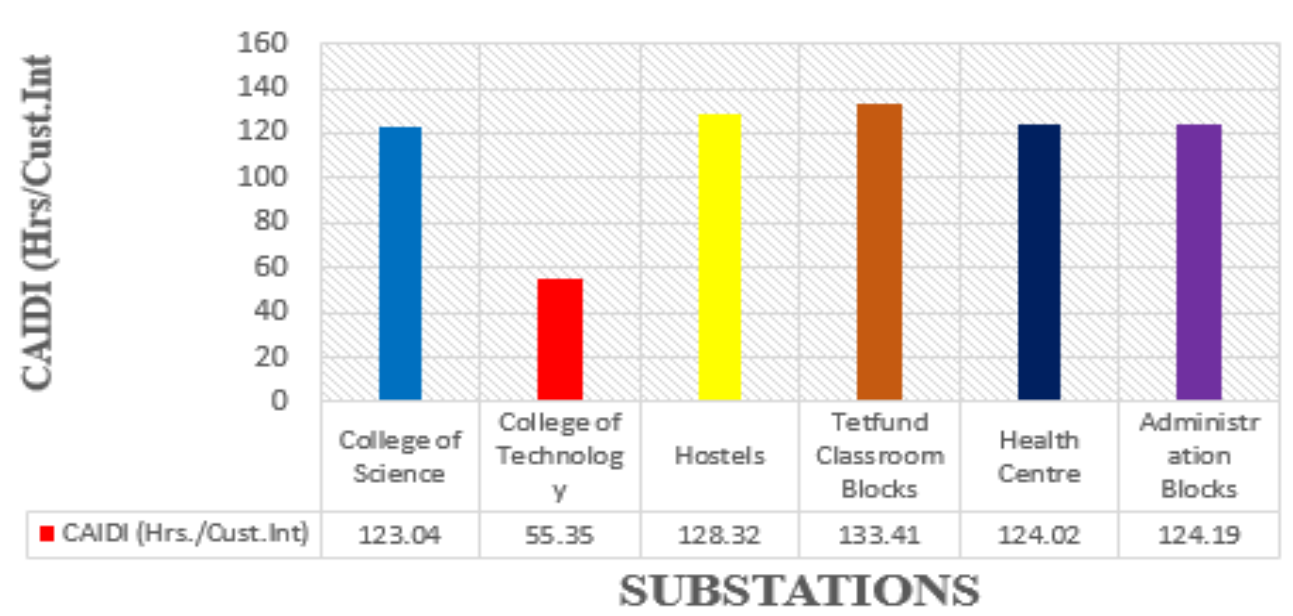

Fig. 10. CAIDI with Respect to Substation.

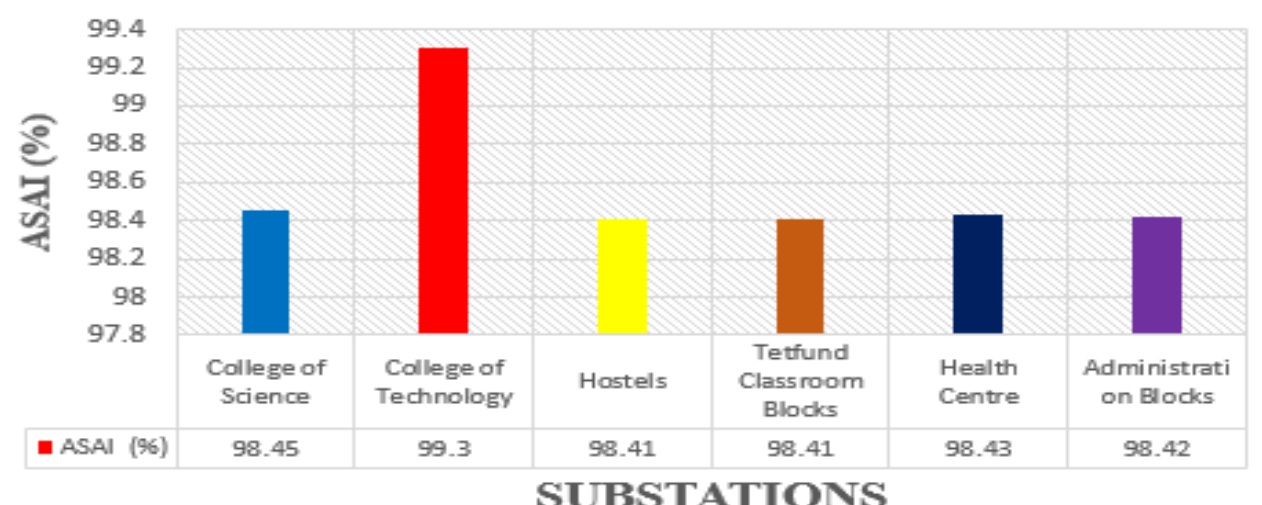

Fig. 11. ASAI with Respect to Substations.

\subsection{Comparison of the Research Results with Reliability Benchmark Indices}

The average with which reliability of a power distribution system is estimated against is known as reliability standards. The standard requirements are provided so as to provide an intellectual reasoning and give appropriate margin for the reliability presentation of power distribution networks. Created on IEEE Std.1366-2011, the standards were computed for power distribution reliability as presented in Table 4.

In Table 3 and Figures 8 - 11 shows the system indices of the substation results. From the results represented in the Table 3 and Figure 10 shows that Tetfund Classroom Blocks has highest CAIDI of 133.41 hours which means on average, customers on this network will experienced power outage more than 133 hours and Figure 9 indicate 
the system SAIDI for the period of one year under review and it was observed that Hostels recorded the highest hours for which the customers were out of power of above 138.50 hours as compared to other substations. In the same vein Figure 8 shows that Administration Block substation customers has highest SAIFI of 1.12 Int/yr., which means it has 1.12 probability of experiencing power outage for the period of one year, with next high exhibited be the College of Science, Health Centre, College of Technology and Hostels respectively with the lowest displayed is Tetfund Classroom Blocks. Finally taking a look at Figure 11 shows the highest ASAI of Collage of Technology network with a value of $99.30 \%$, SAIDI of 60.98hours per year, CAIDI of 55.35hour per outage and SAIFI of 1.10 interruption per year. The average system availability index (ASAI) IEEE standard of utility ought to been documented to have a value of $99.99 \%$ or four-nines. Therefore with the results presented have shown that the system is unreliable and very poor.

Table 4. IEEE Std.1366-2011, the benchmarks Vs. Obtained Analysis results with respect to the substation.

\begin{tabular}{|l|l|l|l|l|}
\hline \multirow{2}{*}{ Substation / IEEE Std. 1366-2011 } & \multicolumn{3}{|c|}{ Reliability Indices } \\
\cline { 2 - 5 } & $\begin{array}{l}\text { SAIFI } \\
\text { (Int. /Cust-yr.) }\end{array}$ & $\begin{array}{l}\text { SAIDI } \\
\text { (Hrs/yr.) }\end{array}$ & $\begin{array}{l}\text { CAIDI } \\
\text { (Hrs/Cust-Int) }\end{array}$ & ASAI (\%) \\
\hline $\begin{array}{l}\text { IEEE Std.13366-2011 } \\
\text { Benchmark }\end{array}$ & $0.6-0.75$ & 1.5 & 1.36 & $99.97-99.99$ \\
\hline $\begin{array}{l}\text { Collage of } \\
\text { Science }\end{array}$ & 1.11 & 135.93 & 123.04 & 98.45 \\
\hline Collage of Technology & 1.10 & 60.98 & 55.35 & 99.30 \\
\hline Hostels & 1.09 & 139.50 & 128.32 & 9841 \\
\hline Tetfund Classroom Blocks & 1.04 & 138.93 & 133.41 & 98.41 \\
\hline Health Center & 1.11 & 137.76 & 124.02 & 98.43 \\
\hline Administration Block & 1.12 & 138.54 & 124.19 & 98.42 \\
\hline
\end{tabular}

\section{CONCLUSIONS}

Electric power system is essentially set up to supply electric power with little or zero interruptions to its consumers. The number of interruptions that happen while the electric power system makes its projected task is part of what defines the general reliability of the system, moreover power utilization has become a significant factor that influences the ambition required for technology to develop and to inspire the improvement of modern society, it is important henceforth to focus attention to the subject matter of reliability of an electric power system. From the study carried out so far, it has been verified that however the frequency of outage affect the reliability, but the outage period has additional influence on the system and on reliability. Administration Block, Petroleum Lab has the highest number of failure rates and Hostels, Tetfund Classroom Blocks had the utmost length of outages. However, it was the Hostels and Tetfund Classroom Blocks that had highest value for system unattainability all over the year. This means that even if there are failures or faults in the network, it is the period for which the outage is certified that critically influence the overall system.

Furthermore, the results also shown that College of Technology is the best reliable in the FUPRE network. Correspondingly, reliability indices of the power system as presented above shows that the availability of power in FUPRE distribution network is beneath universally set standard for utilities. Henceforth, the system can be characterized as unreliable or poor. In future the effect of photovoltaic system at the different load point of the distribution network can be used to improve reliability.

\section{REFERENCES}

[1] Billiton, R., Allan, R.N., Power-system reliability in perspective, IEE Electronics and Power, vol. 30, no. 3, March 1993.

[2] Zima, M., Contributions to security of electric power systems, Dissertation ETH, Swiss Federal Institute of Technology Zurich 2006.

[3] Adebisi, A.A., Reliability evaluation of secondary distribution system in Nigeria: A case study of ayetoro 1 substation, Aguda, Lagos State, Dissertation, Covenant University, Ota, Ogun State, Nigeria, July 2017.

[4] Vrana, T.K., Johansson, E., Overview of power system reliability assessment techniques, RECIFE, 2011, p. 112.

[5] Billinton, R., Allan, R.N., Reliability evaluation of power systems” 1st Edition, Plenum Press, New York, 1996. [6] Aprajita, T., Shilpi, S., Comparative study of reliability assessment techniques for composite power system planning and applications, International Journal of Engineering Research and Applications, 2014, p. 8-13. 
[7] D’Annunzio, C., Generation adequacy assessment of power systems with significant wind generation: a system planning and operations perspective, Thesis, University of Texas at Austin, 2009.

[8] Wang, X., Lin, J., Reliability evaluation based on network simplification for the distribution system with distributed generation, Automation of Electric Power Systems, vol. 34, no. 4, 2010, p. 38-43.

[9] Airiboma, A.E., Ogujor, E.A., Okakwu, I.K., Reliability analysis of power system network; case study of transmission Company of Nigeria, Benin City, Conference paper, 2017 IEEE PES Power Africa, June 2017. 